\title{
Heat Transfer by Natural Convection from a Vertical and Horizontal Surfaces Using Vertical Fins
}

\author{
H. R GOSHAYESHI ${ }^{1}$, F. AMPOFO ${ }^{2}$ \\ ${ }^{1}$ Department of Mechanical Engineering, Azad University of Mashhad (IAUM), Mashhad, Iran \\ ${ }^{2}$ Department of Mechanical Engineering, School of Engineering System and Design, London South Bank \\ University, London, UK
}

\begin{abstract}
Natural convective heat transfer from a heated horizontal and vertical surfaces directly exposed into air which vertical fins, attached to a surface, project vertically downwards has been numerically studied. It has been assumed that the fins are everywhere at the temperature of the surface. The governing equations, written in dimensionless form, have been solved using the finite element procedure. The results show that vertical plate with vertical fins gives the best performance for natural cooling.
\end{abstract}

Keywords: natural convection, horizontal and vertical plate, fins, Nusselt number

\section{Introduction}

The vertical and horizontal plate configurations are the most common geometry for a naturally cooled heat sink. The configuration has been studied by number of researchers. The most commonly used predictive equation for convection was derived by Barcohen, S. \& Rohsenow W [1] and Kruaus, A. D \& Bar-Dohen [2]. This situation has been considered for free convective heat transfer from a heated horizontal and vertical surface directly exposed to air with a free surface to vertical fins attached to surface that project vertically downward into the air has been studied by Smith, H. [3] and Magyaro, L and pep, H [4]. Unlike the well-study vertical/vertical configuration very few research papers have been written on the horizontal/up configuration. The most comprehensive experimental interrogation was performed by Fuji, V. \& Magata, B, [5] but they did not derive an accurate equa- tion which matched the full range of their experimental data. This work compares horizontal plate heat sinks with vertical plate heat sink for natural cooling application. As shown in Figure 1, three different configurations will be discussed: 1) vertical plate with vertical fins 2) horizontal plate with fins facing up 3) vertical pate with horizontal fins. Figure 1 gives some quick guideline on the merits of the different configurations.

\section{Governing Equations and Solution Procedures}

It has been assumed that flow is steady, laminar and two-dimensional and that the air properties are constant except for the density change with temperature which gives rise to the buoyancy forces, this being treated using the goussinesq approach. The following dimensionless variables have then been defined:

$$
\varphi=\varphi^{\prime} / \alpha, \omega=\omega^{\prime} H^{\prime 2} / \alpha, x=x^{\prime} / H^{\prime}, y=y^{\prime} / H^{\prime}, T=\left(T^{\prime}-T^{\prime} c\right) /\left(T_{H}^{\prime}-T_{C}^{\prime}\right)
$$

where $\mathrm{T}$ is the temperature. $T_{H}$ is the temperature of the hot wall and $T_{C}$ is the temperature of the fin. The prime ( ' ) denotes a dimensional quality .

In terms of these dimensionless variables, the governing equations are:

$$
\begin{gathered}
\frac{\partial^{2} \varphi}{\partial x^{2}}+\frac{\partial^{2} \varphi}{\partial y^{2}}=-\omega \\
\frac{\partial \varphi}{\partial y} \frac{\partial \omega}{\partial x}-\frac{\partial \varphi}{\partial x} \frac{\partial \omega}{\partial y}-\operatorname{Pr}\left(\frac{\partial^{2} \omega}{\partial x^{2}}+\frac{\partial^{2} \omega}{\partial y^{2}}\right)=R a \frac{\partial T}{\partial x}
\end{gathered}
$$

$$
\frac{\partial \varphi}{\partial y} \frac{\partial T}{\partial x}-\frac{\partial \varphi}{\partial x} \frac{\partial T}{\partial y}-\left(\frac{\partial^{2} T}{\partial x^{2}}+\frac{\partial^{2} T}{\partial y^{2}}\right)=0
$$

Here $\mathrm{Ra}$ is the Rayleigh number based on the height,

$$
R a=\frac{\beta g\left(T_{H}^{\prime}-T_{C}^{\prime}\right) H^{\prime 3}}{v \alpha}
$$

The above dimensionless equations, subject to the boundary conditions, have been solved using the fin element procedure. The mean heat transfer rate across 
the enclosure has here been expressed in terms of a mean Nusselt number, $\mathrm{Nu}$, based on the height, $H^{\prime}$, the mean heat transfer rate from the lower surface, $q_{m}^{\prime}$ and on and the overall temperature difference, $\left(T_{H i g h}^{\prime}-T_{\text {Low }}^{\prime}\right)$.

\section{Results and Discussion}

The computer program shows that $\mathrm{h}$ convection for horizontal backplane fin channel is lower than $h$ convection for vertical/vertical fin channels. For a given heat sink volume, there exits an optimal fin spacing. The optimum value occurs when two trends are balanced.

If the fins are closely spaced, the heat transfer coefficient $(\mathrm{h})$ is lower because mixing of the boundary layer occurs (the fills up with warm air). The graph if Figure 3 clearly shows that the heat transfer coefficient decreases as the gap between fins decreases. However, if the fins are closely spaced, there is also more dissipating surface area (more fins for a given volume). The additional surface area can counteract the reduced heat transfer coefficient. This can be seen by examining the graph of total wattage dissipated in Figure 4. For the $150 \mathrm{~mm} \mathrm{X} 150$ $\mathrm{mm}$ vertical/vertical heat sink shown in the graph, the spacing of $7.5 \mathrm{~mm}$ provided the optimal combination of heat transfer coefficient and dissipating surface area.

Figure 4, presented above, shows the wattage dissipated for an entire $150 \mathrm{~mm}$ X $150 \mathrm{~mm}$ heat sink, including end fins and radiation (emissivity $=0.1$, typical of a bare extruded surface). When a horizontal baseplate heat sink is sinks in not square, there will be two possible orientations for the fin channel. As shown in Figure 5, the fins should be oriented to provide the shortest channel depth. For a baseplate which $100 \mathrm{~mm}$ X $50 \mathrm{~mm}$, the proper channel orientation will provide $15 \%$ better performance.

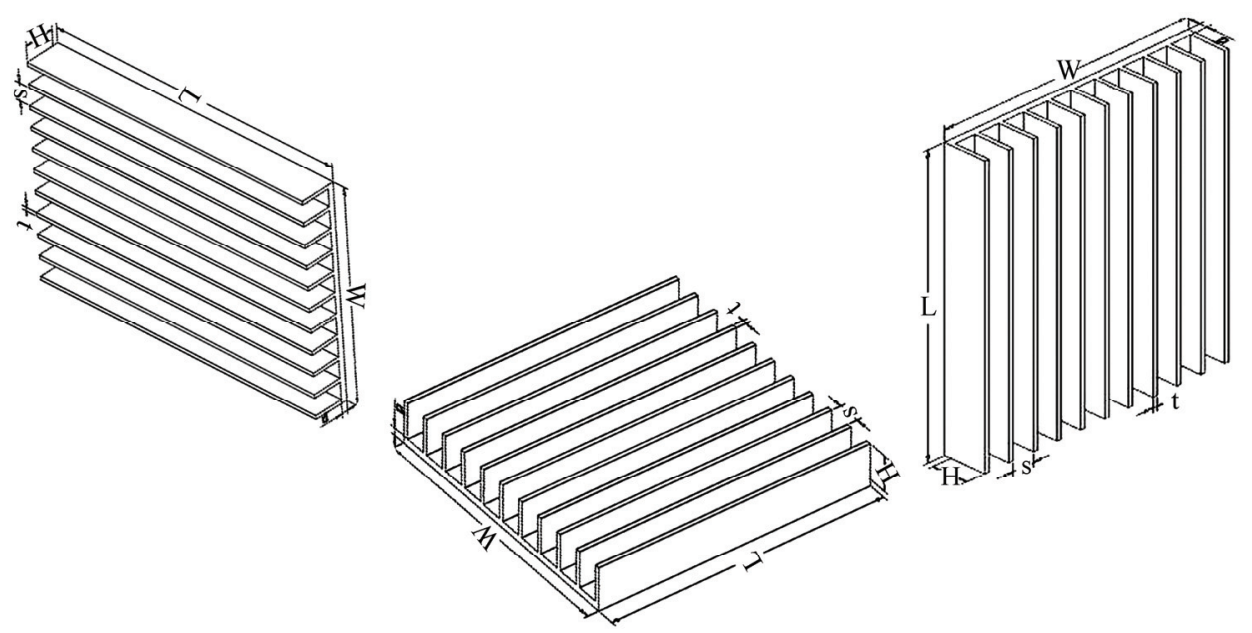

Figure 1. Fin configurations for natural (Free) cooling

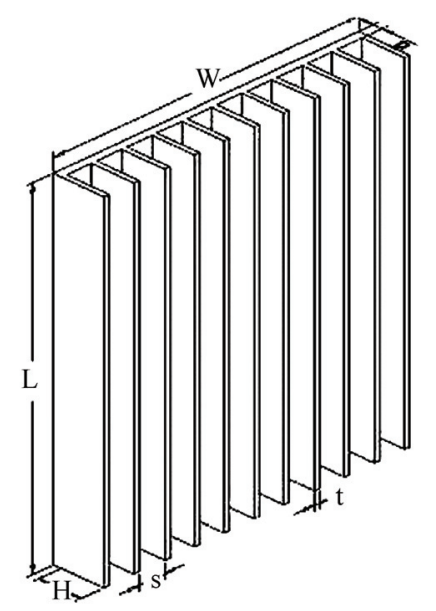

Figure 2. Primary air flow pattern for the vertical/vertical configuration 


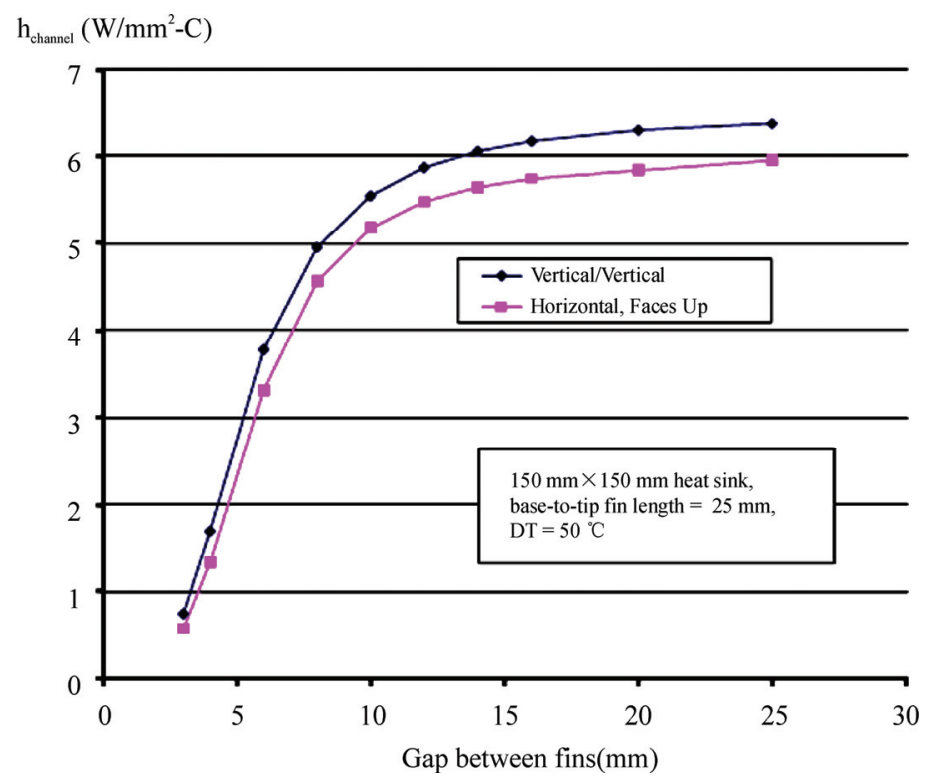

Figure 3. $h_{\text {channel }}$ for vertical and horizontal $150 \mathrm{~mm} * 150 \mathrm{~mm}$ heat sinks

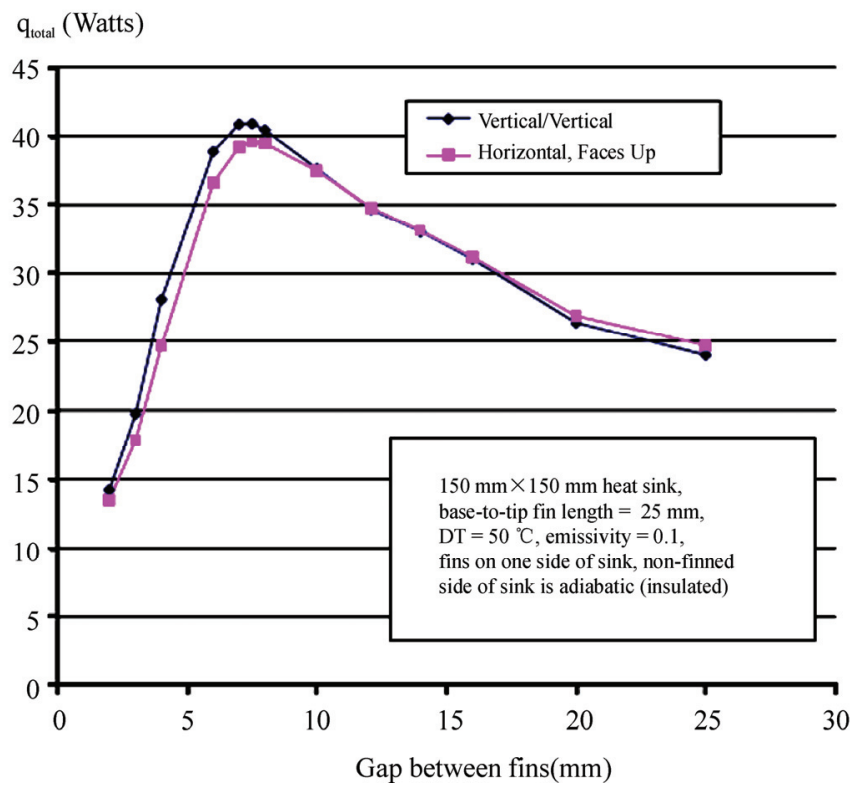

Figure 4. $q$ channel for vertical and horizontal $150 \mathrm{~mm} X 150 \mathrm{~mm}$ heat sinks

\section{Conclusions}

The primary airflow pattern for the vertical/vertical configuration is shown in Figure 6. Air enters nears the bottom of the fin channels and there will be some air flow from the fin tips. Air is heated within the fin channels and exit at the top. With this air flow path, the vertical/ configuration delivers the best performance for free or natural cooling. The final heat sink configuration to be discussed is the vertical baseplate/horizontal fin channel geometry shown in Figure 6.
Figure 7 shows a comparison between vertical/vertical heat sink and a vertical/horizontal heat sink.

As the Figure 7 illustrates, vertical fin channels are better. However it should be mentioned that the vertical/ horizontal sink is certainly better than a flat wall. With a fin length of $25 \mathrm{~mm}$ the vertical/horizontal heat sink provides roughly twice the wattage dissipated, an appreciable improvement. Also, the fins allow for an additional conduction where it is logical to use vertical/horizontal heat sinks. Figures 8 to 10 show the fins configuration by Fluent. 


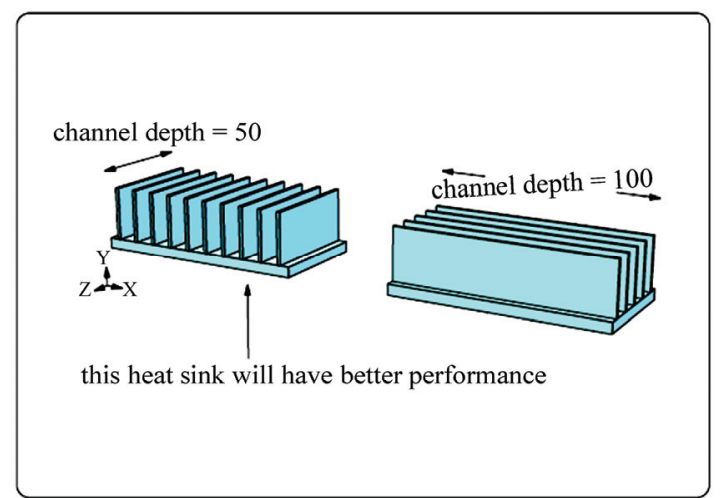

Figure 5. Proper fin channel orientation for horizontal heat sink

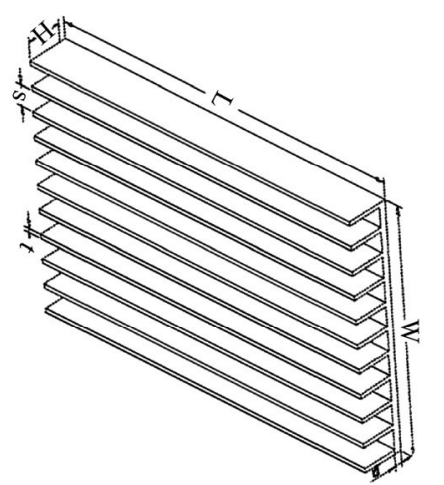

Figure 6. Vertical plate/horizontal fin configuration

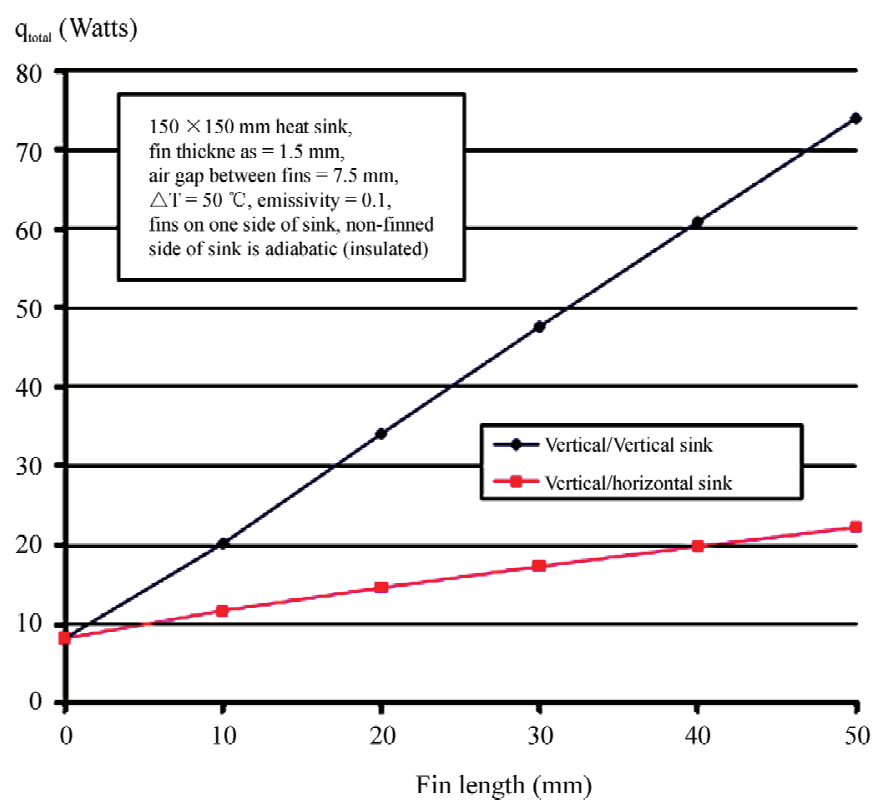

Figure 7. Comparing vertical/vertical and vertical/horizontal heat sinks

The results of the present study indicate that:

- Vertical plate with vertical fins gives the best performance for natural cooling.

- The fin spacing at which the maximum mean heat transfer rate occurs decreases with increasing Rayleigh number varying approximately as $1 / R a^{0.25}$.

- As the fin spacing is decreased, the mean heat transfer rate, provided that the Rayleigh number is high enough for convective motion to occur, initially rises before passing through a maximum and then falling to the pure conduction value.

\section{Nomenclature}

$G^{\prime}=$ distance between bottom of fin and the bottom wall.

$G=G^{\prime} / W^{\prime}$
$H^{\prime}=$ depth of liquid .

$H=H^{\prime} / W^{\prime}$

$N u=$ Nusselt number based on $H^{\prime}$

$\mathrm{Ra}=$ Rayleigh number based on $H^{\prime}$

$T^{\prime}=$ temperature

$T_{C}^{\prime}=$ temperature of top surface

$T_{H}^{\prime}=$ temperature of bottom surface

$T=$ dimensionless temperature

$W^{\prime}=$ half-gap between fins

$W=W^{\prime} / H^{\prime}$

$x=$ horizontal coordinate

$x^{\prime}=$ dimensionless horizontal coordinate

$y^{\prime}=$ vertical coordinate

$y=$ dimensionless vertical coordinate

$\varphi^{\prime}=$ stream function 


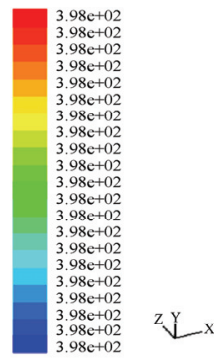

\begin{tabular}{|rr}
\hline Contours of Static Temperature (k) & Nov 15. 2009 \\
\hline
\end{tabular}

Figure 8: Fin configurations for vertical pate with horizontal fins by Fluent

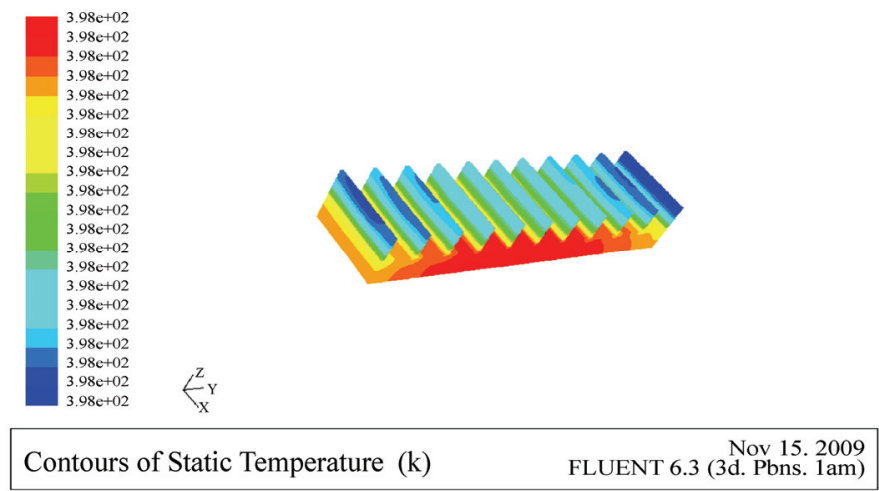

Figure 9: Fin configurations for horizontal plate with fins facing up by Fluent

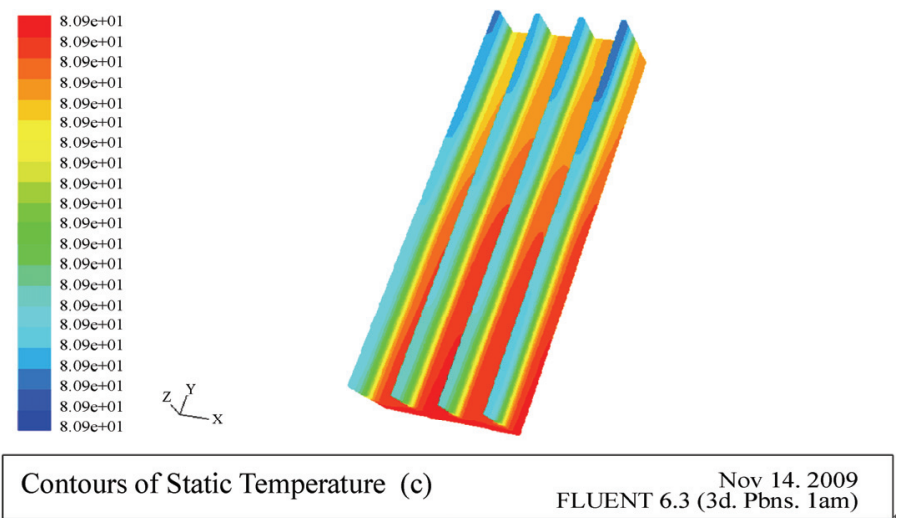

Figure 10: Fin configurations for vertical pate with horizontal fins by Fluent

$\varphi=$ dimensionless stream function

$\omega^{\prime}$ or $\mathrm{u}=$ Velocity

$\omega=$ dimensionless velocity

\section{REFERENCES}

[1] S. Barcohen and W. Rohsenow, "Thermal optimum spacing of vertical natural convection cooled parallel plates," Journal of Heat Treansfer, Vol. 106, pp. 116-123, 1984.

[2] A. D. Kruaus and Bar-Dohen, "A design and analysis of heat sink," John Wiley and Sons, New York, pp. 305-320, 1995.

[3] H. Smith, "Combined heat and mass transfer effect in free convection," Electricity Research Laboratories, Leatherhead, Surrey, February 2006.

[4] L. Magyaro and H. Pep, "Free convection flow pass an infinte vertical plate," ASME Modelling B, Vol. 72, No. 3, 2007

[5] V. Fuji and B. Magata, "MHD unsteady free convection flow through a prous media, Energy Research, Vol. 7, pp. 89-109, 2004. 